\title{
lodine Behaviour During a Severe Accident in a Nuclear Power Plant
}

\author{
Salih Guentay*, Robin C. Cripps, Bernd Jäckel, and Horst Bruchertseifer
}

\begin{abstract}
: lodine is a main fission product of the fuel generated during power operation in nuclear power plants (NPPs). A severe NPP accident can cause fuel, containing fission products (FPs), control rod assemblies and core structures to melt and then release into the containment. The key signatures of iodine behaviour during a NPP severe accident are reviewed, i.e. its release from the molten core in the reactor pressure vessel and transfer via the primary coolant system into the containment. Containment or filter failure would disperse radioactive iodine into the environment. The iodine radioisotopes, ${ }^{131} \mathrm{I}\left(\mathrm{T}_{1 / 2} \mathrm{ca} .8 \mathrm{~d}\right)$ in particular, in sufficient concentrations can pose a health hazard. The overview focuses on the current state of knowledge on iodine behaviour in containment. The formation of volatile iodine species (molecular iodine and organic iodides) by FP-radiation and recent efforts at PSI to suppress their release by reduction to non-volatile iodide for engineered systems are described. Despite extensively available data, further experimental studies are needed to reduce the significant uncertainties in model development. In particular, additional studies on organic iodide formation are required, since these species form the major volatile fraction under certain conditions. Gas phase reactions and the potential effects of many other sump constituents are also important.
\end{abstract}

Keywords: lodine $\cdot$ lodine behaviour $\cdot$ lodine source term $\cdot$ Radiation chemistry $\cdot$ Severe accident

\section{Release of lodine from Degrading Nuclear Fuel}

Iodine is generated during operation of a nuclear power plant (NPP) as a major fission product (FP) in large quantities. Although it is trapped within the ceramic $\mathrm{UO}_{2}$ fuel matrix, a very small amount may diffuse and accumulate in the gap between the fuel pellet and the cladding during power operation. Large amounts are released when the fuel temperature under hypothetical accident conditions exceeds $2100 \mathrm{~K}$. The trapped volatile FPs such as noble gases, caesium

${ }^{\star}$ Correspondence: S. Guentay

Laboratory for Thermal-Hydraulics

PSI

$\mathrm{CH}-5232$ PSI-Villigen

Tel.: +4156 3102677

Fax: +41563102199

E-Mail: salih.guentay@psi.ch and iodine diffuse to pellet surfaces, especially at high temperatures and with molten or breached cladding, which are exposed to a mixture of steam and hydrogen. They are therefore dispersed into the coolant water and mostly escape before the fuel has melted and formed a pool elsewhere.

The main outcomes of numerous experiments are reviewed [1] including laboratory separate-effect tests, e.g. $\mathrm{UO}_{2}$ oxidation and volatilisation studies and FP thermo-chemistry experiments. The latter were conducted to determine the iodine release rate and other FPs from fuel. Empirical and semiempirical models were also developed, such as the temperature dependence of the release rate. It was empirically modelled by an Arrhenius Eqn. (1) [2]:

$k(T)=A(T) \cdot \mathrm{e}^{B(T) \cdot T}$

where $T$ is the temperature in Kelvin and $A(T)$ and $B(T)$ are the temperaturedependent coefficients fitted to correlate the experimental database. Semi-empirical models use a treatment, for example the ELSA model in the IRSN-GRS severe accident code ASTEC [3], by considering the release kinetics being dependent on the rate-limiting process of solid-state diffusion of iodine through the grains of the $\mathrm{UO}_{2}$ fuel matrix of assumed shape and size distribution.
The Phebus Project is an international co-operative effort using a large scale and integral experimental facility [4] [5] to study FP behaviour under realistic conditions. In particular, core damage in the reactor vessel and release phenomena of FPs are investigated. Various severe accident phenomena occurring in the reactor coolant system and in the containment are also studied. Fig. 1 shows the fuel bundle before and after a test. The severe damage (degradation) to the bundle, shown by the radiograph at right, is apparent. Measurements confirm a substantial release of iodine (about $80 \%$ of the initial bundle inventory).

A clear relationship between the release pattern of iodine and other volatile FPs evolving from the bundle and the three distinct degradation phases of the bundle, i.e. main zircaloy oxidation, initial melting of fuel and downward relocation of molten material to lower elevations was established.

A $1000 \mathrm{MW}$ th reactor core contains a total iodine inventory of $6-10 \mathrm{~kg}$, depending on the burn-up (mass to energy conversion) and is burning $\mathrm{UO}_{2}$ or $(\mathrm{U}, \mathrm{Pu}) \mathrm{O}_{2}$ fuel. About $80-90 \%$ of the total inventory is expected to be released from the core if melting is uninterrupted. Under these extreme conditions, the iodine fraction of total released FPs is roughly $3 \%$ and $20 \%$ by mass and activity respectively. 


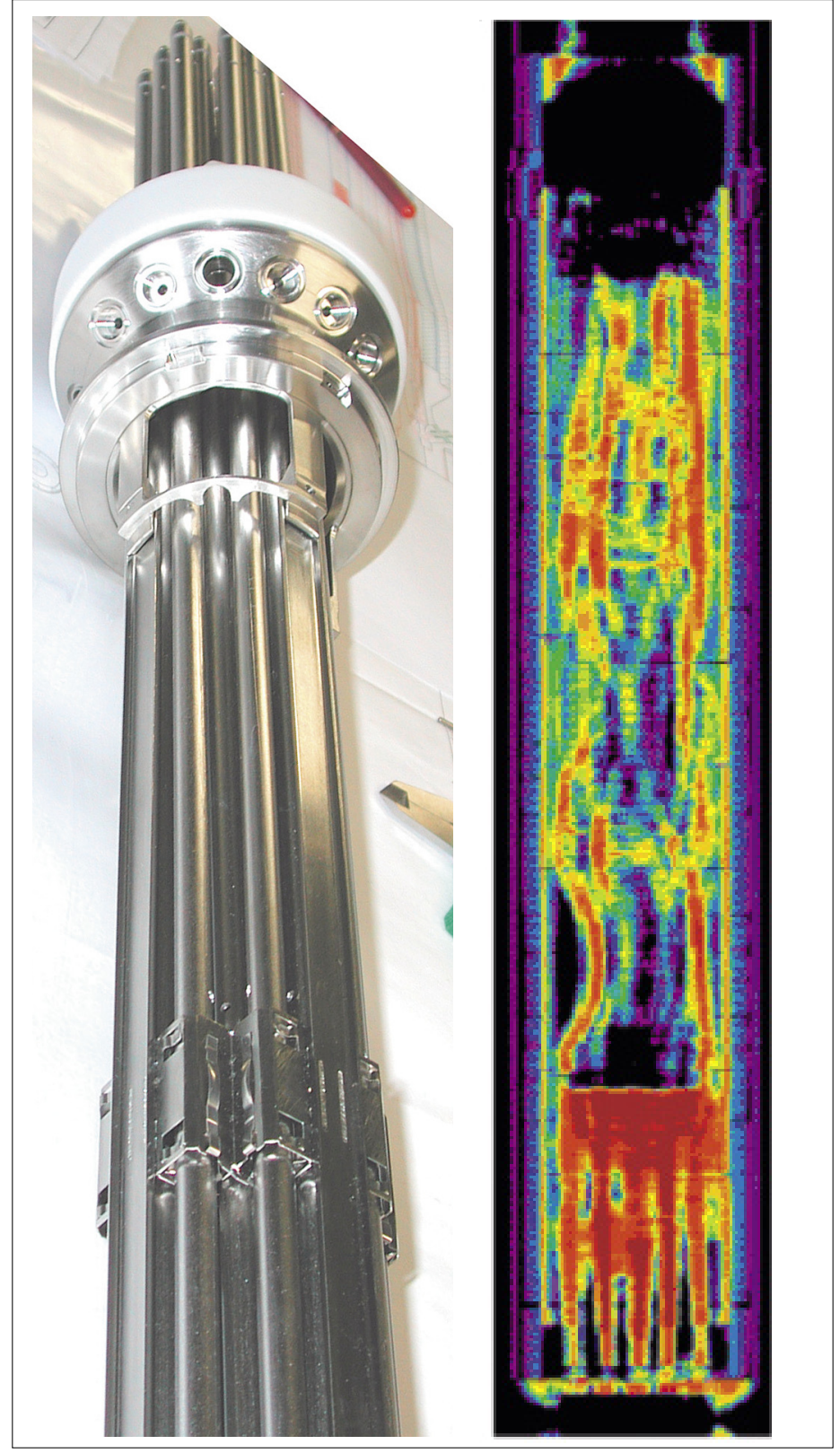

Fig. 1. Pre-test Phebus bundle (left) and radiograph of the post-test bundle (right) showing extensive damage and fuel settling

\section{2. lodine Speciation and Transport in the Reactor Coolant System}

Subjected to high temperature and the duration and extent of oxidizing conditions, FPs and to a minor extent fuel, structural and control rod materials can be either vaporized or volatilised. The latter depends on the formation of volatile species due to oxidation. Metallic and oxide vapours will mix with the steam and hydrogen gas and flow into cooler sections of the primary coolant system. Along the transport path, vapour phase chemical reactions will occur simultaneously with phase changes, which initiate homogeneous and heterogeneous nucleations to produce aerosol particles.

Iodine vapour at high temperature is very reactive and may produce a wide distribution of compounds, which can dy- namically change as the temperature lowers from $2100 \mathrm{~K}$ to about $430 \mathrm{~K}$ in the cold leg (reactor vessel inlet) of the primary coolant circuit or to $700 \mathrm{~K}$ to $1000 \mathrm{~K}$ in the hot leg (reactor vessel outlet). The potentially significant iodine compounds are HI, CsI, $\mathrm{CdI}_{2}, \mathrm{AgI}$, and $\mathrm{BaI}_{2}$ as well as molecular iodine $\left(\mathrm{I}_{2}\right)$. Some reaction rate constants for various vapour phase reactions are known with variable uncertainties and some are only estimates. The gas temperature and the reducing or oxidizing environment and the presence of many reaction partners in the primary coolant system will determine the physical and chemical form of the iodine before it is released into the containment atmosphere. Some fraction of iodine species associated with aerosols will be deposited on the inner surface of the piping by natural removal processes. Similarly a certain fraction of the gaseous iodine species will be depleted in the primary coolant system as a result of surface adsorption. Both removal processes simultaneously occur and will finally determine the amount of iodine species released into the containment.

Due to the high specific decay heat of deposited iodine and other FPs, the deposits on the inner surface of the primary coolant system piping may experience a significant temperature rise. The latter may cause revolatilisation. CsI, for example, appears as an aerosol below about $1100 \mathrm{~K}$. It can vaporise above $1100 \mathrm{~K}$ and flow until it recondenses.

Tests conducted with steam have indicated that the ultimate iodine species is CsI. Its stability at high temperature was then studied experimentally in detail [6]. It was shown that CsI was stable under oxidising conditions up to about $1600 \mathrm{~K}$, whereas it decomposes in low $\mathrm{H}_{2}$ or high $\mathrm{O}_{2}$ concentrations. It was also experimentally shown that sufficient boric acid vapour could cause Cs to form caesium borate rather than caesium iodide [7]. Under such conditions barium iodide became the main species. The Phebus FP tests [5] have indicated that iodine could appear as a mixture of metal iodides depending on the composition of the released vapours as well as on the hydrogen concentration. But the integral tests [5][8] have neither proven nor refuted the existence of CsI as evidenced by the results of earlier separate-effect tests [1]. More importantly, the Phebus tests [5] have also shown the presence of significant amounts of vapour and possibly gaseous iodine at temperatures greater than $700 \mathrm{~K}$. At low temperatures $(420 \mathrm{~K})$, about $2-3 \%$ of the initial iodine bundle inventory was gaseous. These temperatures represent the hot and cold leg of a NPP respectively [4].

The results from the Phebus FP tests up to 2003 have also provided a clear indication that the kinetics of various competing reactions under dynamic boundary conditions, e.g. temperature, could be more important than was previously believed. Therefore, measured iodine speciation under more prototypical accident conditions have probably involved more complex equilibria, rather than simple gas or condensed metal oxides of the type $\mathrm{M}_{\mathrm{x}} \mathrm{O}_{\mathrm{y}}$. It could be one of the main reasons why the transport codes utilizing the equilibrium approach could not produce a successful prediction [9] of the measured iodine speciation in the Phebus circuit.

Up to about 1993, a general consensus was reached on iodine species reaching the containment atmosphere. It was estimated that a maximum of $5 \%$ of the iodine inventory in the core could enter as $\mathrm{I}_{2}$ and the rest as CsI aerosol. The estimate was based on separate-effect in-pile or out-of-pile tests involving fuel bundles or fuel specimens. 
However, the later Phebus FP integral tests [4][5] have demonstrated that the 5\% and $95 \%$ distribution between $\mathrm{I}_{2}$ and metallic iodides might represent an average release for the whole duration of an anticipated PWR severe accident although the timedependent distribution might vary significantly from the average.

The extent of methane produced in the cooler section of the primary piping $(<1000$ ${ }^{\circ} \mathrm{C}$ ) from boron carbide is a further current uncertainty. Boron carbide is used as neutron absorber material in control rods of BWRs, VVERS-1000 and French 1300 Mwe PWRs. Once methane is formed it can react with $\mathrm{I}_{2}$ to form very volatile methyl iodide in the primary coolant system. There is therefore a need to further clarify the behaviour of iodine speciation at high temperature. Further experimental and analytical tasks are planned by the CHIP experimental project (IRSN, France) and by the EU $6^{\text {th }}$ Severe Accident Network of Excellence Project (SARNET) [10] to model the behaviour of iodine species.

In summary, the amount of iodine and its speciation entering into the containment atmosphere is dependent on multiple chemical and physical processes occurring in the primary coolant system.

The transport of the iodine species as described above is modelled in dedicated computer codes [1]. Iodine chemistry together with the chemistry of other FPs is currently based on the thermodynamic equilibria assumption in state-of-the-art severe accident codes [3]. It is assumed that the time needed for iodine reactions to be completed is fast compared to the transport time between temperature zones. The modelled transport of these species depends on the form of the iodine compounds, i.e. gaseous or adsorbed or deposited on aerosol particles.

\section{Containment lodine Behaviour}

Loss of coolant accidents in a nuclear power plant as a result of a break in the primary coolant system will lead to fission products discharged from the break into the containment atmosphere during a severe accident. The coolant water is ejected from the primary system and fills a reserved space, known as the sump, which is located in the basement of the containment building.

Iodine is mainly transferred into the sump by settling of aerosol particles containing iodine species. If available, operation of spray systems can wash out airborne iodine and also improve the rate of particle settling into the sump. Dissolution of metallic iodides is the main source of iodide ions. In addition, the volatile species are transported in the sump via the mass transfer through the gas and aqueous phase inter- face. Volatile iodine species in the gas and aqueous phases are linked with the mass transfer across the phase interface.

Iodine behaviour in the containment and in the primary coolant system is different. For example, containment temperatures are much lower than in the primary circuit so that reactions are often dominated by chemical kinetics.

The majority of chemical reactions take place due to reaction partners, such as radicals, being directly or indirectly formed from radiation. The most of the FP material consists of radionuclides, $\alpha-, \beta-$ and $\gamma$-emitters. Much of this material is either suspended or dissolved in the sump, e.g. ${ }^{137} \mathrm{Cs},{ }^{131} \mathrm{I}$, (stable) ${ }^{127} \mathrm{I}$, and the long-lived ${ }^{129} \mathrm{I}$ or they are airborne, for example, the noble gases ${ }^{85} \mathrm{Kr}$ and ${ }^{133} \mathrm{Xe}$.

\section{1. lodine Chemistry in the Gas Phase}

Gas phase reactions are different from aqueous phase reactions, since for example radicals may freely diffuse in a gas, whereas they are concentrated in water to a small volume surrounding the radiation particle track. Consequently the gaseous radical yields are not very dependent on radiation type. However, despite the simplification most of the iodine studies were focussed on the aqueous phase, since most of the iodine is initially deposited in the sump.

Fig. 2 shows an overview of the important physical and chemical iodine processes. The gas phase chemistry of iodine can be grouped in homogenous and heterogeneous (surface) reactions.

\subsubsection{Homogenous Reactions in the Gas Space}

Gaseous iodine species, mainly $\mathrm{I}_{2}$ and negligible amounts of $\mathrm{HI}$ or $\mathrm{CH}_{3} \mathrm{I}$, after discharge from the primary coolant system undergo reactions with ozone and nitrogen oxides $\left(\mathrm{O}_{3}, \mathrm{NO}_{\mathrm{x}}\right)$. The latter are produced from irradiated air constituents $\left(\mathrm{O}_{2}, \mathrm{~N}_{2}\right)$. The reaction rates are governed by dose rates, concentrations, steam fraction, temperature, humidity, and surface to volume ratios. Ozone readily reacts with molecular and atomic iodine to form non-volatile iodine oxides, corresponding to several oxidation states, such as, $\mathrm{I}_{2} \mathrm{O}, \mathrm{I}_{2} \mathrm{O}_{3}, \mathrm{I}_{2} \mathrm{O}_{4}$, $\mathrm{I}_{2} \mathrm{O}_{5}, \mathrm{I}_{4} \mathrm{O}_{9}, \mathrm{I}_{2} \mathrm{O}_{6}, \mathrm{I}_{2} \mathrm{O}_{7}$, among which, $\mathrm{I}_{4} \mathrm{O}_{9}$ and $\mathrm{I}_{2} \mathrm{O}_{5}$ are expected to be the main reaction products.

These oxides are hydrolysed in steam or in water to form iodate ions. Some experimental programmes [12] have studied the effect of the ozone and iodine concentration ratio, humidity, temperature, dose rate and dose. Notwithstanding the large scatter of data, molecular iodine was consumed within a period of 5-25 h in an irradiated atmosphere after doses of 20-130 kGy.
Free organic radicals are formed from collisions of organic molecules with species like excited nitrogen, oxygen, electrons and positive ions. Organic radicals react with iodine to form iodides such as methyl iodide. Methyl radicals can also be formed by radiolytic abstraction of hydrogen from methane, which is released from the primary circuit of NPPs containing boron carbide as the absorber material for control rods. Several experiments were conducted [13] to understand the effect of dose, oxygen or steam on the organic iodide formation and radiolytic decomposition.

\subsubsection{Heterogeneous lodine Reac- tions with Surfaces}

NPP containments contain large amounts of reactive metals such as stainless steel, aluminium, copper and zinc coatings, which influence iodine behaviour. Some of this material will expose large surface areas to the accident containment atmosphere. Adsorption and desorption of iodine on these surfaces could act either as a sink or a source of volatile species.

Molecular iodine depositing on steel (rate about $1 \cdot 10^{-3} \mathrm{~m} \cdot \mathrm{s}^{-1}$ ) reacts to form ferrous iodide in a condensing environment [14]. Steel under condensing conditions provides a good sink for iodine, since the product ferrous iodide is water soluble and non-volatile.

However, on dry steel, $\mathrm{I}_{2}$ is only physically absorbed. Hence it may desorb from steel, especially in the presence of $\mathrm{O}_{2}$. But the rate is lower than the deposition rate. The affinity of $\mathrm{I}_{2}$ for other metals, such as aluminium, is 100 times smaller than for steel. In contrast, the affinity of $\mathrm{I}_{2}$ for cupper is higher than for steel.

Iodine deposition on organic-based paint surfaces has been extensively researched, since they have large adsorption capacities for gaseous $\mathrm{I}_{2}$ [15] with negligible desorption and react to form organic iodides of differing volatilities, which easily accumulate in the atmosphere. The $\mathrm{CH}_{3} \mathrm{I}$ deposition rate on painted surfaces was at least an order or magnitude slower than $\mathrm{I}_{2}$ and little or none is deposited under condensing steam conditions. Mechanisms of organic iodide production are simplistic and they are still in the formative stage. But based on the evidence [15] formation within the paint surface is suggested.

\section{2. lodine Chemistry in the Aque- ous Phase}

3.2.1. Homogeneous lodine Reactions in the Aqueous Phase

Iodine exists in oxidation states from -1 to +7 and thus potentially forms many compounds. But notwithstanding some areas of uncertainty, e.g. organic iodide formation and the potential effects of many sump constituents, the homogeneous iodine 


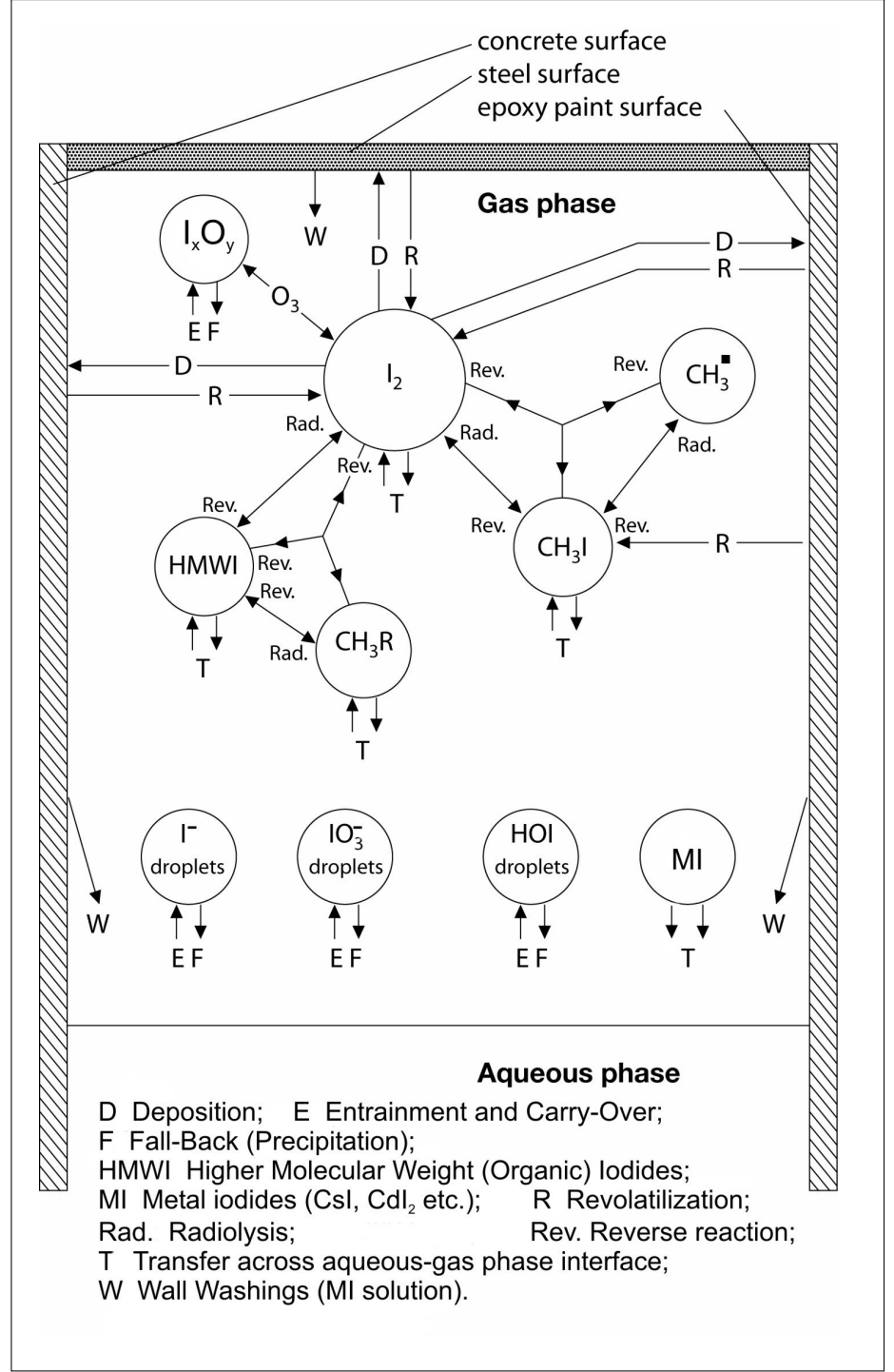

Fig. 2. Processes for iodine reactions in gas phase as modelled in [11]

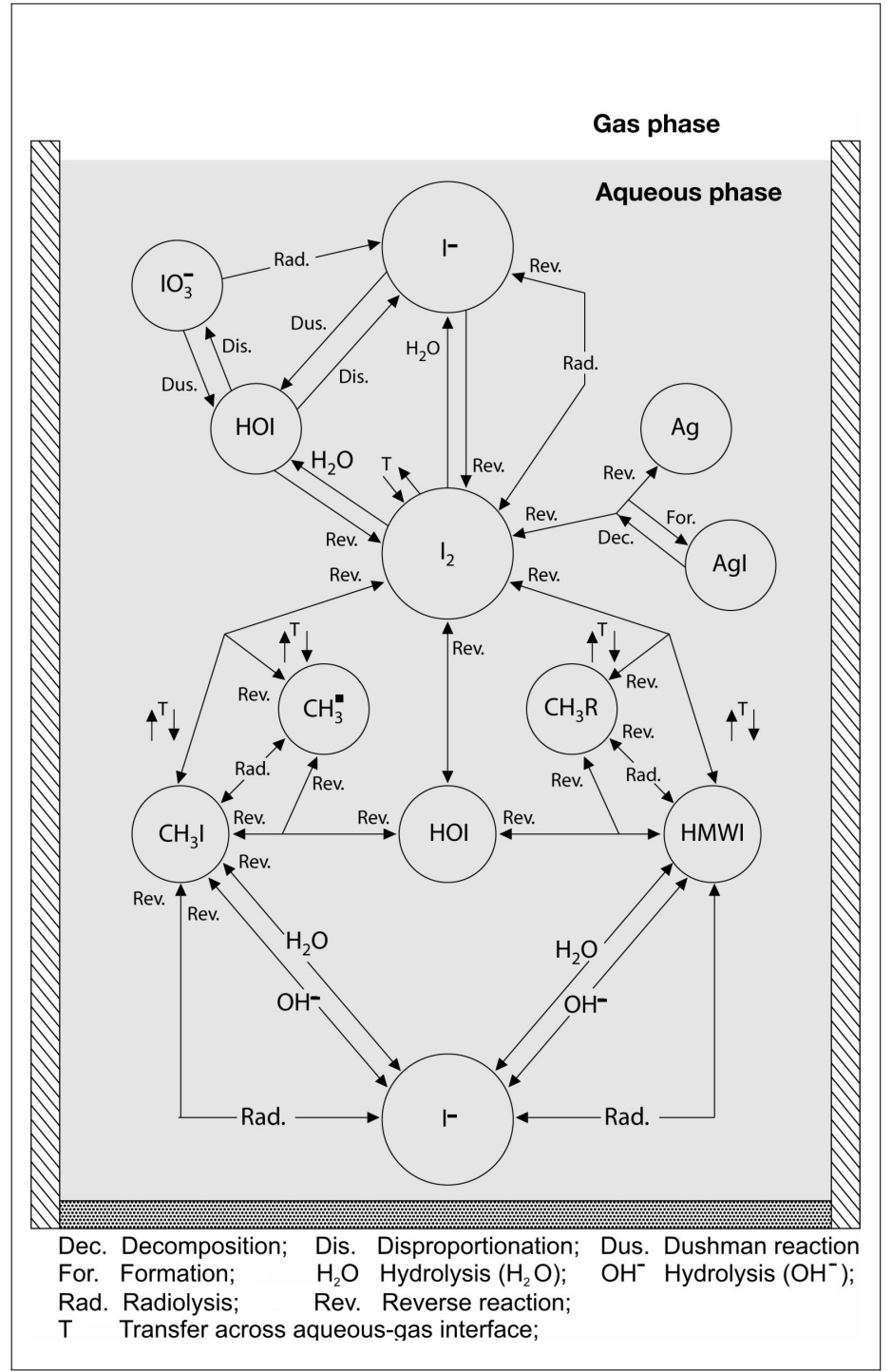

Fig. 3. Main processes of aqueous iodine chemistry modelled in [11] chemistry of the aqueous phase, although complex, is comparatively better established than for the gas phase.

A comprehensive treatment of aqueous iodine chemistry is outside the scope of this paper, but an overview is available [16]. A brief overview of both dissolved species and surface processes and reactions modelled in a computer prediction code [11] is shown in Fig. 3.

\subsubsection{Thermal Reactions}

Molecular iodine hydrolyses in water via an intermediate to hypoiodite (HOI) and iodide (reaction (2)), followed by its disproportionation to iodate and iodide (reaction (3)).

$$
\mathrm{I}_{2}+\mathrm{H}_{2} \mathrm{O} \leftrightarrows \mathrm{HOI}+\mathrm{I}^{-}+\mathrm{H}^{+}
$$

$$
3 \mathrm{HOI} \leftrightarrows \mathrm{IO}_{3}^{-}+2 \mathrm{I}^{-}+3 \mathrm{H}^{+}
$$

The rate of reaction (3) is increased by the catalytic effects of borate or phosphate.
Both reactions are also promoted by high $\mathrm{pH}$. Reaction (4) summarises the hydrolysis and disproportionation. Its reverse reaction is known as the Dushman reaction, but $\mathrm{I}_{2}$ formation is insignificant, since iodide ions are rapidly oxidised by hydroxyl radicals to $\mathrm{I}_{2}$ (see Section 3.2.1.3) rather than by iodate ions under anticipated sump conditions. The reactions are also strongly temperature dependent.

$$
3 \mathrm{I}_{2}+3 \mathrm{H}_{2} \mathrm{O} \leftrightarrows 5 \mathrm{I}^{-}+\mathrm{IO}_{3}^{-}+6 \mathrm{H}^{+}
$$

HOI dissociates significantly (reaction (5)) in strongly alkaline solutions $\left(\mathrm{pK}_{\mathrm{HOI}}\right.$ $\approx 10.6$ ):

$$
\mathrm{HOI} \leftrightarrows \mathrm{H}^{+}+\mathrm{OI}^{-}
$$

If the aqueous phase contains dissolved oxygen, iodide ions are slowly oxidised even at high temperature and low $\mathrm{pH}$ :

$$
2 \mathrm{I}^{-}+1 / 2 \mathrm{O}_{2}+2 \mathrm{H}^{+} \rightarrow \mathrm{I}_{2}+\mathrm{H}_{2} \mathrm{O}
$$

Iodide ions and $\mathrm{I}_{2}$ are in equilibrium with the triiodide ion:

$\mathrm{I}_{3}^{-} \leftrightarrows \mathrm{I}_{2}+\mathrm{I}^{-}$

This reaction can be important at iodide concentrations $>1 \cdot 10^{-4} \mathrm{M}$. Although triiodide is not volatile, $\mathrm{I}_{2}$ formation is favoured by acting as an intermediate during iodide oxidation.

\subsubsection{Radiolysis of Water}

Due to deposited FPs, the sump contains $\alpha-\beta$ - and $\gamma$-radiation sources of considerable dose rates [16]. $\beta$-radiation constitutes a significant fraction of the time-dependent dose rate, since its almost complete absorption in both phases. Water molecules are decomposed by most of the energy deposition to a number of products.

The radiolysis of water produces approximately equal numbers of oxidising $\left({ }^{\circ} \mathrm{OH}, \mathrm{H}_{2} \mathrm{O}_{2}\right)$ and reducing $\left(\mathrm{e}_{\mathrm{aq}}^{-}, \mathrm{H}^{\bullet}\right)$ primary species [17]. They are represented by 
reaction $(8)$ at $25^{\circ} \mathrm{C}$, where the numbers are the radiolytic yields (G-values) in units of $10^{-7} \mathrm{~mol} \mathrm{~J}^{-1}$ :

$\mathrm{H}_{2} \mathrm{O} \leadsto \longrightarrow 2.6 \mathrm{e}^{-}{ }^{-}, 0.6^{\circ} \mathrm{H}, 2.7^{\circ} \mathrm{OH}$,

$0.45 \mathrm{H}_{2}, 0.7 \mathrm{H}_{2} \mathrm{O}_{2}, 2.6 \mathrm{H}^{+}$

After sufficient energy absorption, the covalent bonds in water molecules can dissociate to form fragments with one of the two bonding electrons retained in each fragment. The fragments possessing one or more unpaired electrons are known as free radicals [17] and indicated with a dot next to the formula $\left(\right.$ e.g. $\left.{ }^{\circ} \mathrm{OH}\right)$. Charged free radicals also exist, e.g. $\mathrm{e}_{\mathrm{aq}}{ }^{-}, \mathrm{O}_{2}{ }^{-}$and $\mathrm{I}_{2}{ }^{--}$(see Section 3.2.1.3.). The system is oxidising despite the reducing radical $\left(\mathrm{G}_{\mathrm{e}^{-}}+\mathrm{G}_{\mathrm{H}}\right)$ yields being greater than the yield of the oxidising hydroxyl radical $\left(\mathrm{G}_{\mathrm{OH}}\right)$, due to the conversion of solvated electrons $\left(\mathrm{e}_{\mathrm{aq}}{ }^{-}\right)$ by the slowly forming hydrogen peroxide $\left(\mathrm{H}_{2} \mathrm{O}_{2}\right)$ to ${ }^{\circ} \mathrm{OH}$. In addition, there are some 40 or more reactions of very differing importance involving product combinations and dissolved oxygen to form secondary products [18].

In acidic solutions $(<\mathrm{pH} 5)$, the $\mathrm{e}_{\mathrm{aq}}$ yield decreases to zero if $\mathrm{pH}$ is lowered to 1 , due to the electron reaction with increased $\mathrm{H}^{+}$concentrations to form hydrogen atoms $\mathrm{H}^{\bullet}$. Similarly, in strongly alkaline solutions, the ${ }^{\circ} \mathrm{OH}$ yield decreases to near zero from $\mathrm{pH} 10$ to $\mathrm{pH} 13$ due to dissociation to $\mathrm{H}^{+}$ and oxide ions $\left(\mathrm{O}^{-}\right) \cdot \mathrm{H}_{2} \mathrm{O}_{2}$ also decomposes at high $\mathrm{pH}(>11)$ to the peroxide ion $\left(\mathrm{HO}_{2}{ }^{-}\right)$ [17].

\subsubsection{Radiolysis Reactions Affecting lodine Behaviour}

Iodine volatility is dependent on the oxidizing capacity of the system, which is determined by $\mathrm{pH}$, redox potential, dose, dissolved oxygen concentration, and the removal of volatile iodine from solution.

For example, if a solution of caesium iodide (concentration range $10^{-6}-10^{-4} \mathrm{~mol}$. $\mathrm{dm}^{-3}$ ) and boric acid is irradiated, which typically simulates containment sumps of design basis faults, the simplified reaction steps of iodide oxidation to volatile iodine are:

$\mathrm{I}^{-}+{ }^{\bullet} \mathrm{OH} \rightarrow \mathrm{I}^{\bullet}+\mathrm{OH}^{-}$

$\mathrm{I}^{\bullet}+\mathrm{I}^{-} \leftrightarrows \mathrm{I}_{2}^{\bullet-}$

$2 \mathrm{I}_{2}^{\cdot-} \rightarrow \mathrm{I}_{3}^{-}+\mathrm{I}^{-}$

$\mathrm{I}_{3}^{-} \leftrightarrows \mathrm{I}_{2}+\mathrm{I}^{-}$

Under stronger oxidising conditions, iodide is also oxidised further to non-volatile iodate via intermediates [19]. The primary species, $\mathrm{e}_{\mathrm{aq}}{ }^{-}, \mathrm{H}^{*}$, the superoxide, $\mathrm{O}_{2}{ }^{\cdot-}$ formed from dissolved $\mathrm{O}_{2}$ and $\mathrm{HO}_{2}$ reduce volatile iodine to non-volatile $\mathrm{I}^{{ }^{\circ-}}$ as shown by reactions (13) to (16):

$\mathrm{e}_{\mathrm{aq}}{ }^{-}+\mathrm{I}_{2} \rightarrow \mathrm{I}_{2}^{\cdot-}$

$\mathrm{H}^{\bullet}+\mathrm{I}_{2} \rightarrow \mathrm{I}_{2}^{\bullet-}+\mathrm{H}^{+}$

$\mathrm{O}_{2}^{\cdot-}+\mathrm{I}_{2} \rightarrow \mathrm{I}_{2}^{\cdot-}+\mathrm{O}_{2}$

$\mathrm{HO}_{2}^{\bullet}+\mathrm{I}_{2} \rightarrow \mathrm{I}_{2}^{\bullet-}+\mathrm{O}_{2}+\mathrm{H}^{+}$

They compete with the $\mathrm{I}_{2}$ removal by mass transfer across the water-gas interface from the solution.

\subsubsection{Other Reactions Due to Sump Constituents}

Much kinetic data has been collected up to the 1990s on irradiated pure solutions of iodide in small-scale laboratory experiments. A good degree of confidence (with few exceptions) was achieved on predicting the behaviour in solution under welldefined conditions.

However, in a reactor accident sump, the distribution of water radiolysis products and iodine species are also dependent on the presence of 'impurities', such as other FPs and structural materials. For example, NOx products in the irradiated containment atmosphere, organic materials from decomposing cables, leaching of solvents from paint surfaces and products released from decomposing concrete contribute to an extremely complex and dynamic system. These products may act as radical scavengers or change the redox potential and hence alter the radiolytic and thermal chemistry of iodine species and, in particular, introduce methyl iodide as the most volatile member of iodine compounds into the containment. Following integral Phebus FP test results [4][5], experiments at PSI are underway to evaluate the effects of chloride and nitrate on iodine volatility. Such a physical and chemical system may not be understandable in its entirety, since the direct or indirect effects of identified containment constituents on the iodine chemistry have not yet been sufficiently quantified, but approaches are being followed to attain a database for better predictions of iodine containment chemistry.

\subsubsection{Organic lodide Formation}

Experimental evidence [20] confirms that organic impurities such as methyl ethyl ketone (MEK), methyl isobutyl ketone (MIBK), toluene and xylene, which are the major constituents of vinyl and epoxy paint solvents and thinners, are leached from organic paint surfaces submerged in water. They can change the $\mathrm{pH}$ and redox potential of the irradiated solution. Experimental results have also shown that hydroxyl radicals abstract hydrogen from organic compounds
$(\mathrm{RH})$, yielding organic free radicals $\mathrm{R}^{\bullet}$ and water. The simplest case is the formation of methyl radicals from methane:

$$
\mathrm{CH}_{4}+{ }^{\bullet} \mathrm{OH} \rightarrow \mathrm{CH}_{3} \cdot+\mathrm{H}_{2} \mathrm{O}
$$

In the presence of $\mathrm{O}_{2}$, the (irreversible) peroxidation of the methyl free radical leads to the formation of the methyl peroxyl radical $\mathrm{CH}_{3} \mathrm{O}_{2} \cdot[21]$.

$\mathrm{CH}_{3}+\mathrm{O}_{2} \rightarrow \mathrm{CH}_{3} \mathrm{O}_{2}^{\cdot}$

$\mathrm{RO}_{2}$ radicals then undergo further oxidation to eventually form alcohols, aldehydes, organic acids and carbon dioxide. Since these products are more polarized, the overall effect is to acidify the reaction solution. Organic radicals can form organic iodide by reaction with $\mathrm{I}_{2}$, for example:

$\mathrm{CH}_{3}^{\bullet}+\mathrm{I}_{2} \leftrightarrows \mathrm{CH}_{3} \mathrm{I}+\mathrm{I}^{\bullet}$

In the absence of other reactants, $\mathrm{CH}_{3}{ }^{\circ}$ can also slowly dimerise to form ethane $\left(\mathrm{C}_{2} \mathrm{H}_{6}\right)$. Organic iodides of higher molecular weight are also formed. But they are generally less volatile than $\mathrm{I}_{2}$. In addition, unirradiated experiments suggest that a small, but significant $\mathrm{CH}_{3} \mathrm{I}$ contribution is made by the thermal reaction between $\mathrm{CH}_{4}$ and $\mathrm{I}_{2}$.

The above mechanistic description of organic iodide formation is necessarily simplified. If other organic sources, such as decomposing cables and oil are included, a mechanistic approach to model organic iodide formation and decomposition (see below) is not tenable, given the multitude of potential radical reactions and the large amount of unavailable kinetic data. However, good attempts were made to adopt a simplified and empirical modelling approach [22]

\subsubsection{Decomposition of Organic lodides}

Aqueous organic iodides undergo thermal decomposition in aqueous solution, that is, they hydrolyse and react also with other nucleophilic partners. But $\mathrm{CH}_{3} \mathrm{I}$ hydrolyses very slowly at room temperature without irradiation. At higher temperatures $\left(>100^{\circ} \mathrm{C}\right)$ as shown in Fig. 4, methyl iodide hydrolysis is rapid [23].

In contrast, reducing radicals $\left(\mathrm{e}_{\mathrm{aq}}{ }^{-}, \mathrm{H}^{*}\right)$ decompose $\mathrm{CH}_{3} \mathrm{I}$ much faster at room temperature [24]. The PSI experimental results [25] (Fig. 5, 6) show that radiolytic decomposition yield is proportional to the initial $\mathrm{CH}_{3} \mathrm{I}$ concentration. However, as a result of very low $\mathrm{CH}_{3} \mathrm{I}$ partition coefficient $(<1)$, although the combined decomposition rate of methyl iodide by hydrolysis and radiolysis is quite high at these temperatures, a significant $\mathrm{CH}_{3} \mathrm{I}$ accumulation in the gas phase cannot then be excluded. 


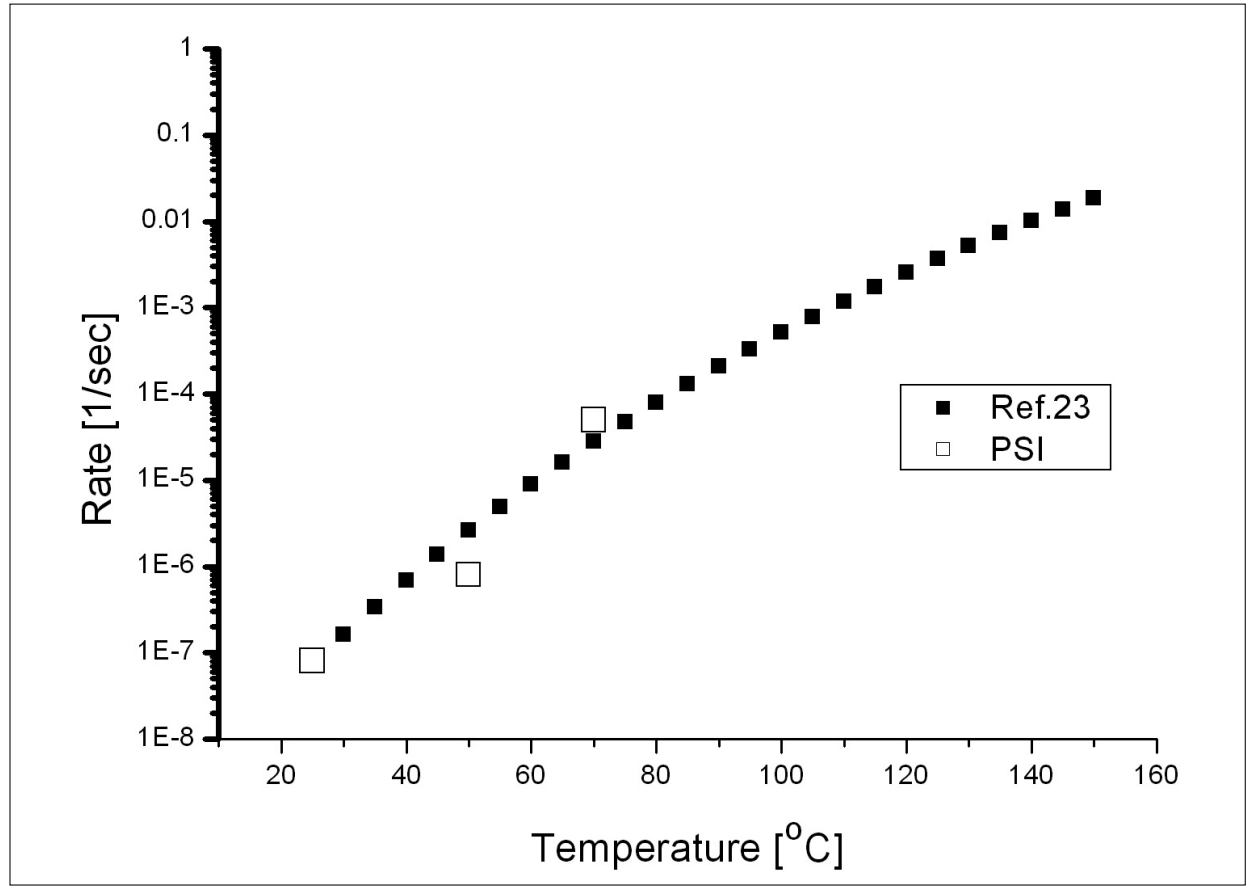

Fig. 4. Temperature effect on methyl iodide hydrolysis

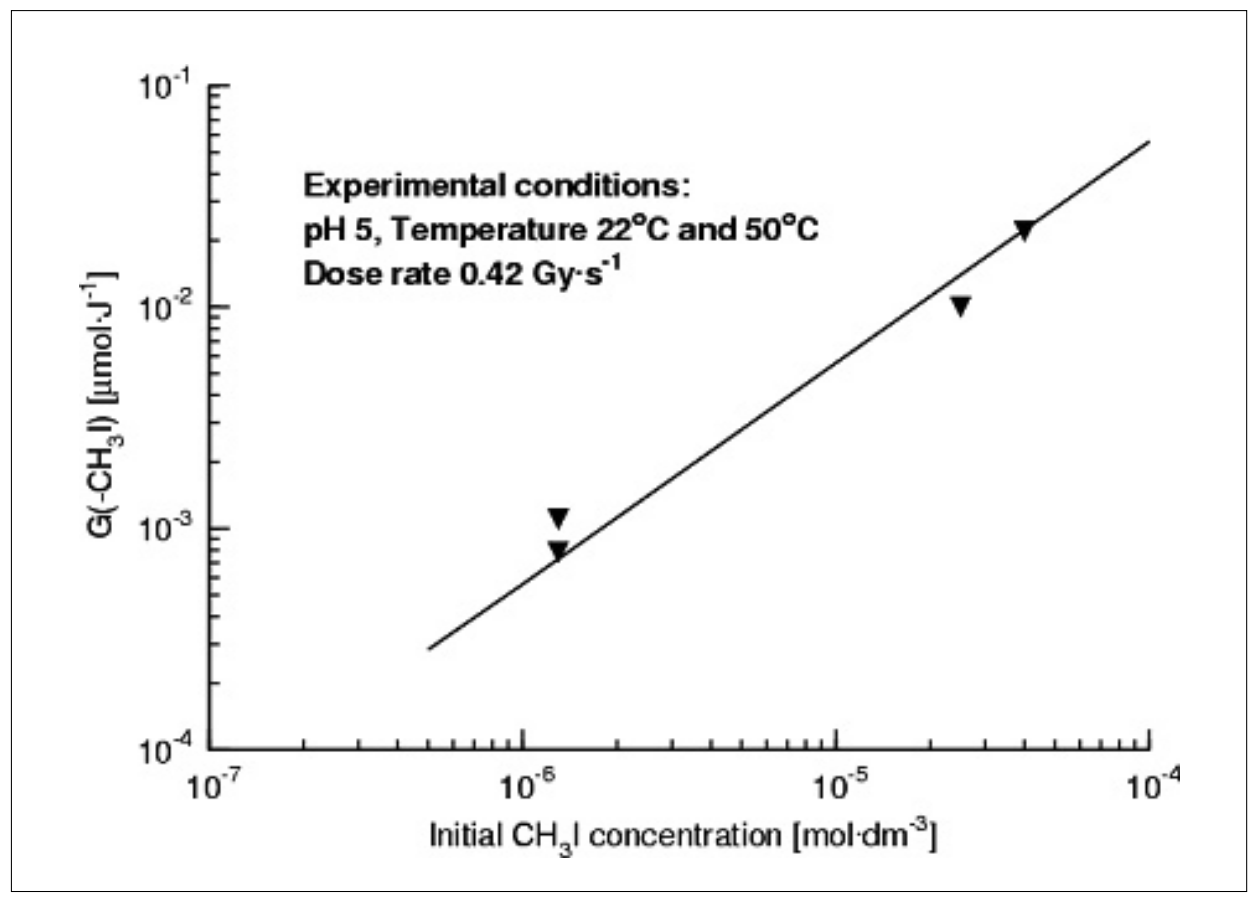

Fig. 5. Effect of initial $\mathrm{CH}_{3}$ I concentration on the radiolytic decomposition yield

Considering the current kinetic data on organic iodide formation and decomposition under all postulated water temperatures, dose rates and $\mathrm{pH}$, a sufficiently fast decomposition of organic iodides is not guaranteed. A need for faster decomposition reactions becomes therefore very important in order to compete both with the very effective removal by mass transfer from solution and the potentially fast $\mathrm{CH}_{3} \mathrm{I}$ formation. To achieve this goal, additional chemical reactants (additives) should be used to increase the rate of thermal decomposition. Research was conducted in 1970s [26] and in 2002-5 at PSI [25] on $\mathrm{CH}_{3} \mathrm{I}$ aqueous solutions with single or multiple candidate additives for potential application in a) containment spray systems, b) sump water conditioning and c) wet containment filters to efficiently vent and trap $\mathrm{I}_{2}$ and RI, by using, for example, sodium thiosulphate solution. However, elimination of further radiolytic oxidation of iodide ions under all foreseeable conditions cannot be excluded.

Test results, using PSI-developed analytical techniques [25] (Fig. 6), have indicated that, under gas sparging conditions, the $\mathrm{CH}_{3} \mathrm{I}$ decomposition rate by thiosulphate ions was insufficient to eliminate volatility. Therefore to improve the overall rate, secondary additives are being studied.

\subsubsection{Silver-lodine Reactions}

Since metallic silver, released from PWR control rods, or $\mathrm{Ag}^{+}$ions react with iodine, silver is considered an efficient iodine sink. However, the radiolytic stability of AgI under all anticipated conditions must also be considered.

\subsection{Silver lodide Formation}

Silver iodide is formed via a non-catalysed heterogeneous reaction of molecular iodine with metallic silver surfaces:

$$
2 \mathrm{Ag}+\mathrm{I}_{2} \rightarrow 2 \mathrm{AgI}
$$

However, the reaction rate is proportional to exposed surface area, and then once the AgI layer is formed, on the diffusion rate of iodine through the layer. Experimental results have shown that the times for half completion of the reaction varied by about an order of magnitude, i.e. 3 or $33 \mathrm{~min}$ for rapidly stirred or unstirred $\mathrm{Ag}^{0}$ suspensions in $\mathrm{I}_{2}$ solutions respectively [28]. But the overall $\mathrm{I}_{2}$ consumption rate was much lower than any mass transfer rate causing an efficient $\mathrm{I}_{2}$ removal from the solutions.

Silver particle surfaces can be oxidized $\left(\mathrm{Ag}_{2} \mathrm{O}\right)$ in the containment atmosphere before they settle into the sump. They react then very efficiently with iodide ions since oxidised silver dissolves in water to form $\mathrm{Ag}^{+}$:

$\mathrm{Ag}_{2} \mathrm{O}+2 \mathrm{I}^{-}+2 \mathrm{H}^{+} \rightarrow 2 \mathrm{AgI}+\mathrm{H}_{2} \mathrm{O}$

The reaction proceeds until the surface oxide is consumed. In the presence of nitric acid AgI formation was reported to be rapid [28], presumably due to fast oxidation of the silver surfaces. In contrast, chloride ions, anticipated from cable pyrolysis, appear to prevent reaction of iodide with silver oxide at $\mathrm{pH} 7$.

\subsection{Silver lodide Radiolytic Decomposition}

PSI experiments were conducted using colloidal AgI suspensions under different oxidising conditions and acidic $\mathrm{pH}$ ranges and using a dissolved, i.e. in situ $\beta$-radiation source [27][29] (Fig. 6). The results have shown that, depending on the initial colloid concentrations, a very small to an almost complete AgI decomposition was observed (Fig. 7). Some experiments were repeated under almost identical conditions but using $\gamma$-radiation (unpublished results). In the absence of chloride ions, practically no AgI decomposition was observed.

The difference in AgI decomposition behaviour, when a different radiation type is selected, is being investigated. However, 


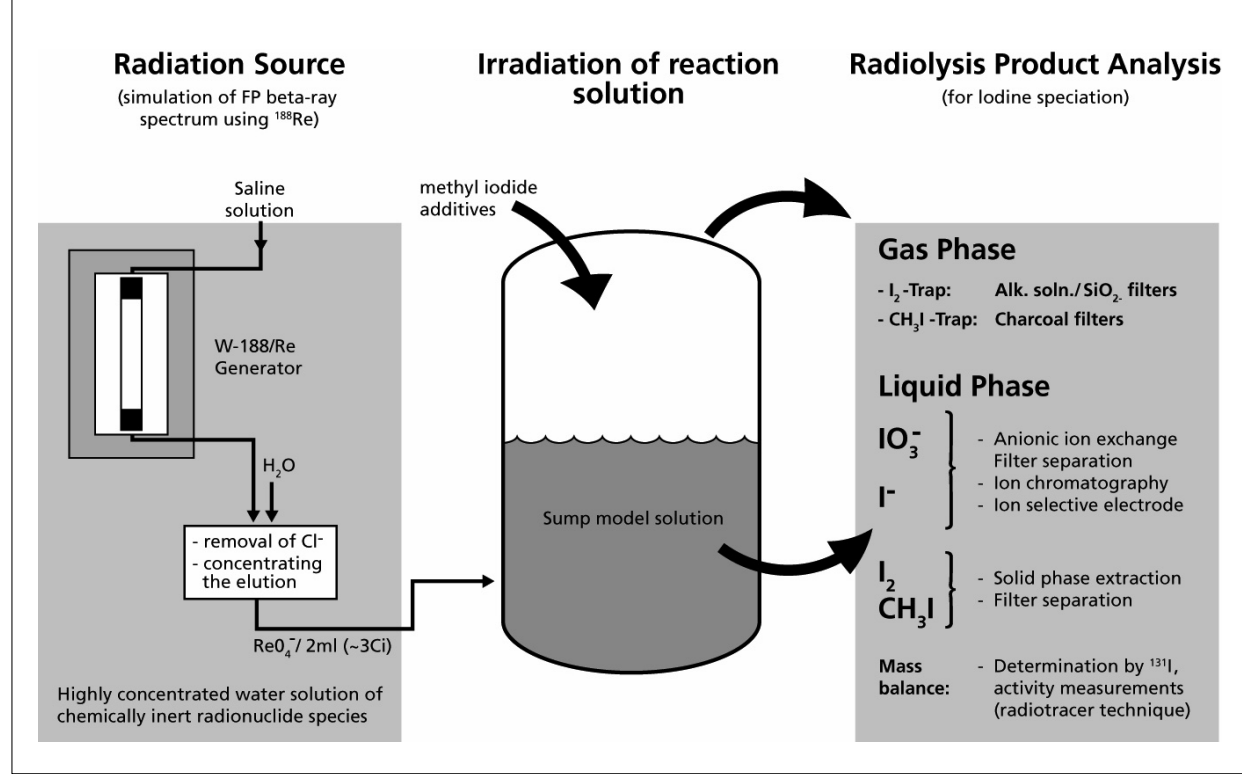

Fig. 6. PSI irradiation facility and development of the analytical procedure

chloride ions at low $\mathrm{pH}(2-3)$ can effectively release $\mathrm{I}_{2}$ from $\mathrm{AgI}$ colloids with either in situ $\beta$ - or $\gamma$-radiation.

Once separated from AgI particles, iodine is then a partner in various homogeneous reactions under prevailing conditions. Hence AgI decomposition may not necessarily only lead to volatile iodine.

\subsection{Heterogeneous lodine Reac- tions with the Immersed Stainless Steel and Paint Surfaces}

Experimental data suggest that dissolved $\mathrm{I}_{2}$ also reacts with steel surfaces to form soluble metal iodides, which dissociate into $\mathrm{Fe}$ cations and iodide ions. Consequently, the net $\mathrm{I}_{2}$ concentration on the steel surfaces is zero and hence no surface saturation occurs. The overall process is therefore the reduction of dissolved $\mathrm{I}_{2}$ to non-volatile iodide ions. Another possible route for RI generation is the reaction of dissolved $\mathrm{I}_{2}$ with immersed paint surfaces analogous to the gas phase.

\subsection{Mass Transfer of lodine Be- tween the Aqueous and Gas Phases}

Volatile iodine species can cross the interface between the aqueous and the gas phases if concentration gradients exist between them. The transfer rate of a volatile species from the gas to the aqueous phase is given by Eqn. (22):

$\mathrm{C}_{r}$ and $\mathrm{C}_{\mathrm{w}}$, are the gas and aqueous phase $\frac{\mathrm{d}_{\mathrm{g}}}{\mathrm{dt}}=-\frac{K \cdot A}{V_{g}}\left(C_{g}-\frac{C_{w}}{R}\right)$

Where $\frac{1}{\mathrm{~K}}=\frac{1}{k_{g}}+\frac{1}{P \cdot k_{w}}$ from the containment atmosphere into the sump.

The final distribution of each species in order to attain their equilibrium concentrations is defined by their partition coefficients. Partition coefficients reduce as temperature increases and they are species-dependent. For example, the partition coefficients of molecular iodine are 83 and 3 , whereas those for methyl iodide are 8 and $<0.8$ at $25^{\circ} \mathrm{C}$ and about $120^{\circ} \mathrm{C}$, respectively. But iodine species in any phase can be depleted by other processes, such as a containment leak and equilibrium concentrations will not be attained.

\subsection{Engineered Systems to Miti- gate Accumulation of Volatile lodine Species to Prevent Their Release into the Environment}

Containment sprays are designed to condense steam to avoid a pressure increase in the containment. If available, they can wash iodine species from the atmosphere and transfer them into the sump water. If clean water is used, the droplets can absorb $\mathrm{I}_{2}$ and to a lesser extent $\mathrm{CH}_{3} \mathrm{I}$. However, absorption depends on the spray droplet characteristics, mass flow rate, droplet fall time and the mass transfer rate of the iodine species into the droplets. If the spray water does not contain agents for fast reduction of the iodine species, the washing efficiency for $\mathrm{CH}_{3} \mathrm{I}$ is inadequate. Droplets may transfer iodine back into the containment atmosphere once the spray system re-circulates sump water. Maintaining the sump $\mathrm{pH}$ at very high values $(>10)$ could be the basis of another engineered system to suppress $\mathrm{I}_{2}$ generation and further release. But operating NPPs are not currently equipped for high $\mathrm{pH}$ control due to design and installation difficulties. in hot and alkaline sump water will in crease the rate of airborne iodine transfer concentrations respectively, $\mathrm{A}$ and $\mathrm{V}_{\mathrm{g}}$ are
the interfacial surface area and the gas phase volume, $\mathrm{P}$ is the volume partition coefficient, which is defined as the ratio of trations of a given species at equilib The mass-transfer coefficients, $\mathrm{k}_{\mathrm{w}}$ and $\mathrm{k}_{\mathrm{g}}$ or the aqueous and the gas phases respecand the concentration gradient over the mass transfer rates if the former (species production or consumption) are faster than the latter. For example, rapid $\mathrm{I}_{2}$ hydrolysis

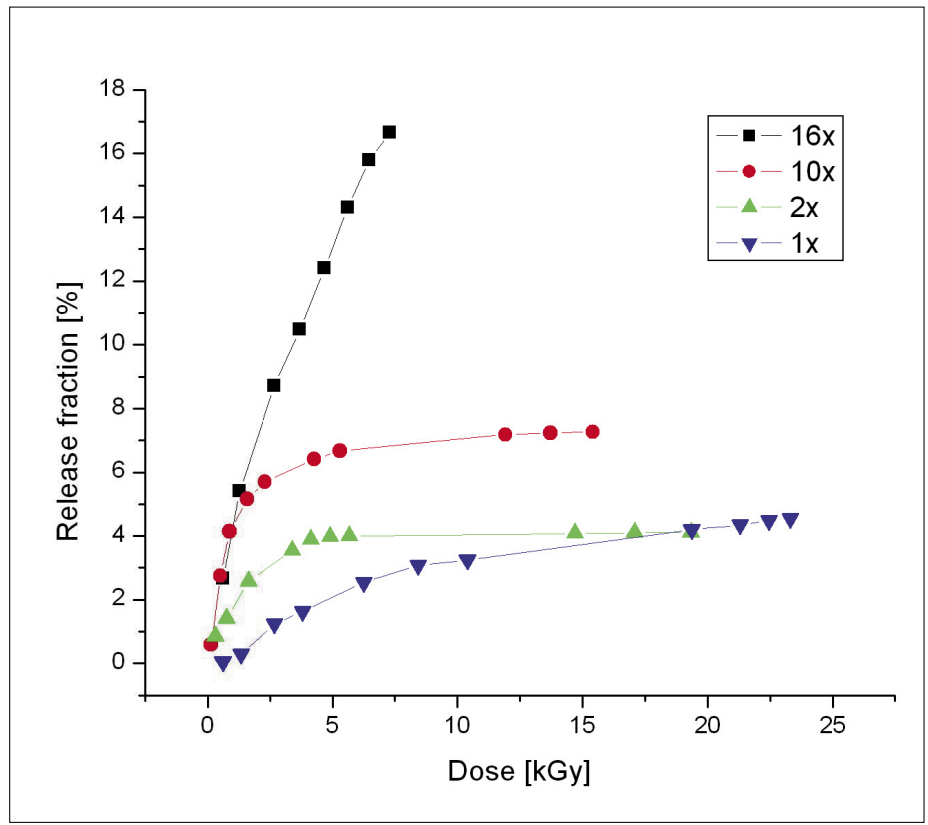

Fig. 7. $\mathrm{I}_{2}$ released fraction versus absorbed dose from in situ $\beta$-irradiated Agl colloidal suspensions of different initial concentrations. 
Wet scrubbers are used as filters for containment venting. They usually contain alkaline sodium thiosulphate solutions to achieve an initial high $\mathrm{pH}(>10)$, to reduce $\mathrm{RI}$ and $\mathrm{I}_{2}$ to iodide. Provided that the incoming gas and the soluble aerosol particles do not acidify the solution, the $\mathrm{I}_{2}$ decontamination factor for currently installed scrubbers should be at least 100 as stipulated by national NPP regulatory authorities. The corresponding decontamination factor for organic iodides has not been systematically investigated since the authorities have not yet defined it.

\section{Modelling of lodine Chemistry}

Since the chemistry in the containment is complex and convoluted, it is necessary to simulate the iodine chemistry in kinetic computer models. There are two modelling approaches, i.e. mechanistic and empirical:

a) Mechanistic models contain detailed sets of chemical reaction equations including many intermediate species using published kinetic data. Such models are complicated and sufficient knowledge of the mechanisms and kinetic data may not be available so that educated guesses for postulated reactions must be applied. But they are applicable to a wide range of conditions. The LIRIC [22] and INSPECT [31] computer codes are examples in current use.

b) Empirical codes contain far fewer equations and each equation simulates the effect of chemical equation sets and parameters to model the main phenomena in the containment. The validity of the models is dependent on correlations obtained mainly from integral experimental data covering a wide range of relevant conditions. Hence their predictions for other conditions outside the validation range may not be reliable. IMPAIR3 [11], IODE (ASTEC) [32], and IMOD [30] are current and widely known examples.

The data obtained from various research projects, e.g. ACE, RTF, CAIMAN, SIEMENS, PSI, and PHEBUS FP were used to develop and assess both types of codes [33]. Although all the codes do predict the separate-effect test results to a good degree, they fail to produce adequate predictions for large-scale integral tests, such as the PHEBUS FPT1 test [4].

\section{Release into the Environment}

The amount of activity release into the environment from accident containment is dependent on whether the containment remains intact or breached, the leak rates, and the controlled release via the containment filtered venting system.

The Three Mile Island (TMI) Unit 2 Accident (March 28, 1979, Harrisburg USA) was a so-called 'terminated accident' so that only partial core damage occurred and an intact containment ensued. Hence iodine releases to the environment were negligible.

In contrast, during the accident in Chernobyl Unit 4 (April 25, 1986, Ukraine), half of the iodine was released, since the plant was not of western design and standards. Many local children were exposed to radiation doses sufficient to lead to thyroid cancers. Initial radiation exposure in contaminated areas was due to the short-lived iodine-131. Significant exposure occurred via incorporation, i.e. via food, contaminated milk, and inhalation.

The definition of permissible levels for iodine as for other FPs released from the containment during a severe accident depends generally on the regulatory practices. For instance, $1 \%$ of the iodine inventory (mass) of a $1000 \mathrm{MWth}$ reactor core has been defined [34].

It is therefore extremely important to improve knowledge of principal routes for volatile iodine production in the containment and mitigation paths to convert volatile iodine to non-volatile species. The reduction of uncertainties in the modelling will further improve the quality of safety evaluations to demonstrate that the potential iodine source into the environment is below regulatory requirements and will thus not cause any ill health.

\section{Conclusions}

Given the undisputed hazard of sufficient FP iodine in the environment, intensive research efforts were made in the last few decades to study its generation in fuel, release during a severe accident involving core melt, its transport and processes affecting its speciation in NPP systems. Many bench-and a few integral experimental tests have provided, in particular, much information on the process routes for volatile iodine generation. A large kinetic database was produced on thermal and radiolytic reactions in the aqueous phase under clean and controlled conditions. Such data were used to validate both types of codes to predict iodine behaviour. However, the current state of knowledge of gas phase reactions of iodine and organic iodide formation lags somewhat behind the knowledge for the aqueous phase. Efforts are also being applied to extend knowledge on the effects of important sump constituents, such as nitrate, chloride and other FPs etc.

This paper has provided a limited overview of the main facets of iodine behaviour, starting with its release from the degraded core until its possible release into the envi- ronment. It has also described important active and natural mechanisms to mitigate iodine release into the environment. However, the authors have attempted to elaborate on the current understanding and research activities with the aim to convey an idea of the significant need for a better understanding of iodine systems and therefore to reduce the uncertainties.

Received: August 2, 2005

[1] A.L. Wright, B. Adroguer, A. Alonso, B.R. Bowsher, U. Brocmeier, D.S. Cox, R.R. Hobbins, K.-D. Hocke, F. Iglesias, A.V. Jones, D.E. Leaver, J.A. Martinez, D.A. Powers, I. Shepherd, 'Primary System Fission Product Release and Transport, A State-of-the-Art Report to the Committee on the Safety of Nuclear Installations', NUREG/CR-6193, NEA/CSNI/R(94)2, ORNL/TM-12681, 1994.

[2] R.A. Lorenz, J.L. Collins, A.P. Malinauskas, 'Technical Basis for Estimating Fission Product Behaviour during LWR Accidents', NUREG-0772, 1981.

[3] H.J. Allelein, K. Neu, J.P. Van Dorsselaere, N. Tregoures, M.K. Koch, M. Bendiab, L. Kubisova, Nucl. Eng. Des. 2003, 221, 95.

[4] B. Clemént, N. Hanniet-Girault, G. Repetto, D. Jacquemain, A.V. Jones, M.P. Kissane, D. von der Hardt, Nucl. Eng. Des. 2003, 226, 5 .

[5] N. Girault, S. Dickinson, F. Funke, E. Krausmann, H. Bruchertseifer, R. Cripps, D. Powers, A. Auvinen, L. Herranz, R. Caponetti, M. Ogino, 'FPT1 Containment Chemistry Interpretation Circle, Final Interpretation Report', DPAM/SEMIC (2004) 06 Phebus FP IP, 545, 2003.

[6] 'Nuclear Aerosols in Reactor Safety', Supplementary Report, by an NEA Group of Experts, Nuclear Energy Agency, (66 8412 1) ISBN 92-64-12652-X, 1985.

[7] I.M. Shepherd, Y. Drossinos, Nucl. Technol. 1995, 110, 181.

[8] M.L. Carboneau, V.T. Berta, M.S. Modro, 'Experiment Analysis and Summary Report for OECD-LOFT Project Fission Product Experiment', LP-FP-2, OECD LOFT-T-3806, 1989.

[9] B. Clemént, T. Haste, 'Comparison Report on International Standard Problem ISP46 (Phébus FPT-1)', OECD/NEA/CSNI, 2004, 18.

[10] J.C. Micaelli, M. Schwarz, V. Teschendorff, G. Cognet, W. Scholtyssek, R. Sehgal, R. Sairanen, 'SARNET: Sustainable Integration of EU Research on Severe Accident Phenomenology and Management', Proc. FISA 2003, Conclusion Symposium on Shared-Cost and Concerted Actions, EUR 21026.

[11] S. Güntay, R. Cripps, 'IMPAIR/3: A Computer Program to Analyse the Iodine Behaviour in Multi-Compartments of a LWR Containment', PSI Report, 128, 1992. 
[12] F. Funke, P. Zeh, S. Hellmann, 'Radiolytic Oxidation of Molecular Iodine in the Containment Atmosphere', Proc. OECD Workshop on Iodine Aspects of Severe Accident Management, Vantaa (Helsinki), Finland, May 18-20, Report OECD/ NEA/ CSNI/R(99)7, 1999, p.79.

[13] S. Dickinson, H.E. Sims, F. Funke, S. Güntay, H. Bruchertseifer, J.-O. Liljenzin, K. Liger, T. Montanelli, E. Krausmann, A. Rydl, 'Iodine Chemistry and Mitigation Mechanisms (ICHEMM)', EU FISA 2003 Symposium, November 10-12, 2003.

[14] J.C. Wren, G.A. Glowa, J. Merrit, J. Nuc. Mat. 1999, 265(1-2), 161.

[15] S. Hellmann, F. Funke, G.-U. Greger, A. Bleier, W. Morell, 'The Reaction between Iodine and Organic Coatings under Severe PWR Accident Conditions - An Experimental Parameter Study', Ed. S. Güntay, Proc. 4th CSNI Workshop on the Chemistry of Iodine in Reactor Safety, Ed: Würenlingen, Switzerland, June 1012, 1996, Report NEA/CSNI/R(96)6, p. 345.

[16] K.H. Neeb, 'The Radiochemistry of Nuclear Power Plants with Light Water Reactors', Walter de Gruyter, Berlin, New York, ISBN 3-11-013242-7, 1997.

[17] J.W.T Spinks, R.J. Wood, 'An Introduction to Radiation Chemistry', Third Edition, John Wiley and Sons, New York, ISBN 0-471-61403-3, 1990.

[18] A.J. Elliot, 'Rate Constants and G-Values for the Simulation of the Radiolysis of Light Water over the Range 0-300 ${ }^{\circ}$ C', AECL-11073, COG-94-167, AECL, Chalk River, Ontario, Canada, 1994.

[19] G.V. Buxton, R.M. Sellers, J. Chem. Soc., Faraday Trans. 1985, 81, 449.

[20] P. Driver, G. Glowa, J.C. Wren, Radiat. Phys. Chem. 2000, 57(1), 37.

[21] J.C. Wren, J.M. Ball, G.A. Glowa, Nucl. Technol. 1999, 125(3), 337.

[22] J.C. Wren, J.M. Ball, Radiat. Phys. Chem. 2001, 60, 577.

[23] R. Borkovski, 'Untersuchungen zum chemischen Verhalten des Methyliodides bei schweren Störfällen in Druckwasserreaktoren', KfK Report 3968, Karlsruhe, 1985.

[24] G.V. Buxton, H.E. Sims, Radiat. Phys. Chem. 2003, 67, 623.

[25] L.F. Parsley, Nucl. Appl. Techn. 1970, 8, 13.

[26] H. Bruchertseifer, R. Cripps, S. Güntay, B. Jäckel, 'Experiments on the Retention of the Fission Product Iodine in Nuclear Reactor Accidents', PSI Scientific Report 2003, IV, ISSN 1423-7334, 2004, 71.

[27] B. Jäckel, R. Cripps, S. Güntay, H. Bruchertseifer, Appl. Radiat. Isot. 2005, 63(3), 299.

[28] F. Funke, G.-U. Greger, A. Bleier, S. Hellmann, W. Morell, 'The Reaction between Iodine and Silver under Severe PWR Accident Conditions - An Experimental Parameter Study', Ed. S. Güntay, Proc. 4th CSNI Workshop on the Chemistry of Iodine in Reactor Safety, Würenlingen,
Switzerland, June 10-12, 1996, Report NEA/CSNI/R(96)6, p.283.

[29] S. Güntay, R.C. Cripps, B. Jäckel, H. Bruchertseifer, Nucl. Technol. 2005, 150(3), 303.

[30] J.C. Wren, G.A. Glowa, J.M. Ball, 'A Simplified Model for Iodine Containment Chemistry and Transport: Model Description and Validation using Stainless Steel RTF Test Results', Proc. OECD Workshop on Iodine Aspects of Severe Accident Management, Vantaa (Helsinki), Finland, May 18-20, 1999, Report OECD/ NEA/ CSNI/R(99)7, p.327.

[31] S. Dickinson, H.E. Sims, Nucl. Technol. 2000, 129, 374.

[32] N. Alpy, M.P. Kissane, I. Drosik, C. Fiche, M.H. Kaye, 'Fission Product Transport in the ASTEC Integral Code: The Status of the SOPHAEROS Module', Proc. 8th Int. CNS CANDU Fuel Conf., 21-24 Sept., Muskoka, Ontario, Canada, 2003.

[33] Prepared by J. Ball, C. Marchand, H. Allelein, L. Cantrel, R. Cripps, G. Glowa, L. Herranz, A. Rincon, J. Royen, A. Rydl, P. Schindler, G. Weber, C. Wren, 'International Standard Problem (ISP) No. 41, Follow up Exercise: Phase 2', OECD/ NEA/CSNI/R(2004)16, 2004.

[34] HSK, 'Nuklearer Notfallschutz auf der Basis des HSK-Referenzquellterms für potentielle schwere KKW-Unfälle in der Schweiz', Dezember, 1994. 